\title{
Research on International Carbon Trading Game Behavior
}

\author{
Ming Zeng ${ }^{1}$, Shiyu Meng ${ }^{1,}$, Liyi Tian ${ }^{1}$, Zhuhan Long ${ }^{1}$, Chenjun Sun ${ }^{2}$ \\ ${ }^{1}$ School of Economics and Management, North China Electric Power University, Beijing 102206, \\ China \\ ${ }^{2}$ State Grid Hebei Electric Power Company, Hebei 050000, China \\ a799079198@qq.com
}

Keywords: Game theory, Carbon Trading, International Carbon Game.

\begin{abstract}
The research on the development of the international carbon trading game is one of the hot topics in the academic community. On the basis of absorbing the previous achievements of carbon game research, the paper analyzes the problems existing in the process of carbon market in China and studies its development system. From the perspective of game theory, the paper studies the status of carbon trading mechanism in global interests and analyzes the game of interests between countries and puts forward corresponding suggestions for the development of China's carbon market.
\end{abstract}

\section{Introduction}

At present, the international carbon emission trading market is mainly concentrated in the EU regional markets and local trading systems such as the United States, Canada, and Australia. According to the differences in carbon emissions trading mechanisms, international carbon emissions trading is divided into mandatory quota trading markets and voluntary carbon emissions trading markets. The former is represented by the European Union. The core is that countries allocate their own emission allowances based on their total emissions and companies can trade the remaining emissions allowances. The latter is represented by the United States and Canada, mainly referring to the voluntary commitment of governments, enterprises, and some other social entities to legally-enforced reductions in the total amount of greenhouse gas emissions. Under the circumstance that the global climate environment has been severely tested, carbon emissions trading is favored by more and more regions. Different foreign markets have launched trials of carbon emission trading models in an attempt to seize the commanding height of future carbon emissions trading markets.

\section{International Carbon Trading Preconditions}

To cope with the global climate change crisis, the reduction of greenhouse gases can be achieved through international cooperation. One of them is the realization of the international carbon trading mechanism. However, the operation of international carbon trading mechanisms must rely on the integrity of three preconditions.

The world's emission space is determined, that is, the choice of target $\mathrm{CO}_{2}$ concentration in the atmosphere must be reasonable. One of the foundations of international carbon trading is the determination of the total carbon emission rights. All international carbon trading is conducted around carbon credits. Therefore, the total amount of global greenhouse gas emissions must be established, otherwise it will lead to confusion in the advanced carbon trading mechanism. (2) There are differences in the cost of emissions among countries, that is, the economic conditions of different countries. Each country has its own special national conditions, which has led to differences in the emission reduction costs of various countries. Because of this imbalance, carbon emission rights can be circulated as a special commodity in the international market.

There is a difference in the emission space of each country, that is, countries must obtain reasonable carbon emission rights. Carbon trading is a form of property rights trading, so the initial allocation of carbon emission rights is a technical and political problem. The developed countries should bear the main responsibility for the current total amount of greenhouse gas emissions. The 
huge historical, per capita and consumer carbon emissions have led to the current climate change crisis. Therefore, a reasonable carbon emission right is the cornerstone of the success of the international carbon trading market mechanism.

\section{Significance of Game Theory in the Study of Carbon Trading Mechanism}

Internationally, the games between countries have both the game between developed countries and the game between developed and developing countries. Within the country, there are games between the government and enterprises and financial institutions, games between enterprises, and games between the government and citizens. Any country in the control of carbon emissions is faced with the dilemma of maintaining environmental and economic development.

Under the general trend of low-carbon economy, especially the demand for global carbon emission reduction demand, carbon finance may become a breakthrough for the development of low-carbon economy. Low-carbon economy, especially carbon emission reduction rights, has very large quasi-financial attributes. The carbon emission reduction right has become a value currency symbol following the mass commodity of petroleum. This triggeres the development of carbon futures carbon money, carbon banking, carbon trading and other carbon financial derivative products around these carbon emission reduction rights.

Carbon gambling means that in international climate change negotiations and each country acts according to its own information to make an action strategy that is beneficial to its own interests. In the process of developing low carbon economy, each player uses their own advantages and strategies to choose their own behavior to achieve their own goals. That is to say, the result of international carbon game is the result of interaction between countries through research and action. Out of the common knowledge of the international ecological environment, each country adopts corresponding strategies by analyzing and studying the situation of other players.

It can be seen that in the development of a low-carbon economy, the strategy tactics of various parties have been studied in a game theory, and a quantitative model has been established. This will solve the problems in the low-carbon economy and deal with the thorny issues of balancing the interests of all parties, which will provide scientific basis to further provide the impetus for the development of China's low-carbon economy.

\section{Analysis of Carbon Game Behavior between Countries}

The development of a low-carbon economy not only involves conflicts in the interest of various countries in the economy, but also competes in politics and in the international status and discourse of each country. This kind of political power struggle has already been clearly revealed at the beginning of the development of a low-carbon economy. Global temperature rise caused by carbon emissions has been raised to the level of global security, rising temperatures have seriously threatened the safety of human society. The issue of global warming has been incorporated into the UN Security Council's political agenda and becomes a global political issue.

Therefore, reduce carbon and carbon emiooions has been given the property of defining the world order. The new political game between the international community has also begun. The political game revolves around the global climate governance and the maintenance of the right to human survival. Governance of the global climate and the establishment of a global climate order are closely related to the fundamental interests of economic development in all countries of the world. The powers and obligations of countries in the global climate order, the "emission reduction rules" have become the new focus of the political game among big countries, and countries are frequently trying to develop low-carbon economies.

Because countries in the world have different situations in terms of carbon emissions, countries adopt different attitudes in solving carbon emissions issues, and there are major differences in the carbon emissions reduction targets. The change in the low-carbon economy originated in the United Kingdom, and Europe's low-carbon economic development leads the world. Therefore, the EU, 
which mainly includes Germany, the United Kingdom, and France, is in a dominant position in reducing carbon emissions. In the issue of reducing carbon emissions, the EU has forced the U.S. and China to pay a higher price in the name of maintaining human survival and coping with global climate and seek to define the soft power of the world order. In such a game, the strategy of the participant is whether to develop a low-carbon economy, and its revenue is to assume responsibility for carbon emission reduction, so that the country's status in the international economy and politics is improved.

However, developing a low-carbon economy and reducing $\mathrm{CO}_{2}$ emissions may have a negative impact on a country's economy, making it difficult for participants to choose. Due to the capital strength and technological advantages of developed countries, they occupy the main positions in the development of the international low-carbon economy order, so they have the first-mover advantage in the game, while the developing countries are caught in a dilemma. Because, in developing countries, developing a low-carbon economy, the national economy that has just begun to develop will suffer; if it does not develop a low-carbon economy, then the right to speak in international affairs will diminish, especially for China. For large developing countries, it is a more difficult issue.

For developed countries, under the provisions of the "Tokyo Protocol", it is necessary to fulfill rigid emission reduction requirements. However, all developed countries hope that this part of the obligations will be borne as little as possible, or even by developing countries. The developed countries hope to develop in favor of their economic status, but they are also facing the contradictory choice of developing low-carbon economy international political status and economic growth. In the game of low-carbon economy in the category of countries and countries, the political and economic game between the two camps in developed and developing countries is the main part.

\section{Relevant Suggestions on the Development of China's Carbon Market Under the International Carbon Game Environment}

In the international process of low carbonization, although from the perspective of the economic man, the games between countries in the economic, political and other aspects are inevitable. Through analysis, we can clearly see that only when all countries adopt a cooperative attitude and jointly join in the development of a low-carbon economy and energy-saving and emission-reduction team can global environmental issues be resolved more effectively and a win-win situation can be achieved. Of course, in view of the above issues, it is also necessary for China to adopt certain measures to develop carbon trading mechanisms and establish a carbon market so as to obtain a favorable position in the international carbon emissions trading game.

In the game of national interest, under the premise of other countries fulfilling low-carbon economy, reducing emission reduction obligations has a positive effect on the economic development of a country. As a developing country, China assumes the responsibility of energy saving and emission reduction and takes the initiative to play a role in the international low-carbon economy and the political arena. Economic construction is still the focus of the government's work; Second, it resists the obligation of developed countries to impose emission reduction obligations on our country, reiterating historical emissions, and ensuring that national interests are not violated.

The effectiveness of developing a low-carbon economy by relying solely on a country's isolation is not obvious, and it must rely on effective communication and cooperation with the country. At present, China's experience in developing a low-carbon economy, funds, and technologies for energy-saving and emission reduction are all insufficient. Whether considering unilateral interests or considering long-term international goals, we need to actively cooperate with developed countries. The first is to explore the mechanism of cooperation between the leaders of the United States, Europe, and Japan and establish a three-level cooperation system between the leaders' summit, high-level leadership committees, and technical working groups. The second is to identify strategic areas that can generate shared intellectual property rights, and to cooperate in the research and development of low-carbon energy technologies in the early stage of commercialization.

The global carbon emission reduction resources, especially the CDM resources, are mostly in China. According to a plan of the United Nations Development Program, our current carbon emission 
reduction accounts for one-third of the world's total, ranking second in the world, and it has become the most potential carbon emission reduction market. However, the development of China's carbon financial system and related policies and measures have lags behind and are at a low end in international carbon trading. The bargaining power of carbon trading is very weak, especially because of the pricing and carbon binding of carbon trading rights, and the renminbi is not yet an internationally-denominated currency and does not have the right to speak. The amount of CDM carbon emission reductions sold by Chinese companies is mainly mediated by international carbon companies. In fact, the pricing power is controlled by the hands of international financial institutions. In the development of carbon finance, China does not have the majority of discourse power and dominance. To make the low-carbon economy run in a healthy and orderly manner, it is imperative to step up the construction of a carbon finance framework.

The development of a low-carbon economy is bound to be contrary to the interests of certain domestic interest groups, and it is also different from people's traditional understanding and habits. In order to ensure the smooth development of a low-carbon economy, appropriate enforcement measures are necessary. First, a legal system for developing a low-carbon economy should be established. Establish the status of low-carbon, energy-saving and emission-reduction from the legal level, carry out legislation on the "Climate Change Law", and add clauses involving low-carbon development, and then gradually formulate and improve the legal and institutional system for addressing climate change during the revision of relevant laws and regulations.

\section{Conclusion}

The carbon game between countries is first reflected in the game of carbon emission space and the game of carbon emission rights. China's participation in the setting of carbon emission space and the initial analysis of carbon emission rights is in need of the principle of common but different. The principle of carbon emission space setting and distribution of emission rights is the fundamental principle that each country has formed in the process of developing economic and carbon emission reduction and dealing with the relationship between each other, which is the guiding principle of global warming. Therefore, the study of carbon gambling behavior plays a very important role.

\section{Acknowledgments}

The paper is supported by the Science and Technology Program of SGCC (Analysis of global energy Internet game behavior supported by big data technology).

\section{References}

[1]. An J, Lee J. A Newsvendor Non-Cooperative Game for Efficient Allocation of Carbon Emissions. Sustainability. 2018.

[2]. Hambel C, Kraft H and Schwartz E S. The Carbon Abatement Game. Social Science Electronic Publishing. 2018.

[3]. Liu X, Sun Y and Gao W. A Game Analysis on Carbon Verification Data Authenticity under the Influence of Carbon Emissions Rights Initial Allocation Policy. Contemporary Economic Management. 2017.

[4]. Yang L I, Gan H C and Economics S O. A Game Theory Analysis of the COP Negotiation on Carbon Emissions. Scientific \& Technological Management of Land \& Resources. 2017.

[5]. Zhao L W. Nonlinear Complex Dynamics of Carbon Emission Reduction Cournot Game with Bounded Rationality. Complexity. 2017(12).

[6]. Shi-Jian W U, Sun X Y and Yang P. Game analysis of carbon emission regulation under dual governance system. China Population Resources \& Environment. 2017. 
[7]. Zhang Y, University S N. Evolutionary Game Analysis of Low-Carbon Production in Government-Regulated Enterprises. Journal of Shandong Institute of Commerce \& Technology. 2017. 